\title{
Fórmula hidrolisada na prevenção da doença alérgica em idade pediátrica: revisão baseada na evidência
}

Luciana Ornelas, ${ }^{1}$ Raquel Andrade, ${ }^{2}$ Isabel Abreu ${ }^{2}$

\section{RESUMO}

Objetivo: Rever a evidência existente acerca da eficácia da suplementação com fórmulas hidrolisadas na prevenção de doença alérgica em crianças de termo.

Fontes de dados: The Cochrane Database, MEDLINE/PubMed, National Guideline Clearinghouse, Guideline Finder e Canadian Medical Association.

Métodos de revisão: Pesquisa de normas de orientação clínica, meta-análises, revisões sistemáticas e ensaios clínicos aleatorizados e controlados, entre janeiro de 2009 e janeiro de 2019, em inglês e limitado a estudos em humanos. A query de pesquisa incluiu os seguintes termos MeSH: Protein Hydrolysates; Hypersensitivity; Allergy and Immunology; Rhinitis; Allergic, Seasonal; Asthma. Para a atribuição dos níveis de evidência e forças de recomendação utilizou-se a Strenght Of Recomendation Taxonomy (SORT), da American Academy of Family Physicians.

Resultados: Foram encontrados 23 artigos, dos quais três cumpriram os critérios de inclusão: duas meta-análises e um estudo de coorte. Apenas um dos estudos incluídos apresentou resultados estatisticamente significativos na redução da doença alérgica. Os restantes estudos não demonstraram evidência na redução da doença alérgica.

Conclusões: Após a análise dos artigos concluiu-se que não existe evidência científica na utilização de suplementação com leite hidrolisado para a prevenção da doença alérgica (força de recomendação B). Considera-se que são necessários mais estudos, com qualidade superior, que validem a evidência encontrada e auxiliem na formulação de hipóteses.

Palavras-chave: Fórmula hidrolisada; Doença alérgica.

\section{INTRODUÇÃO}

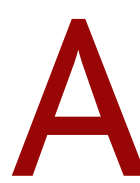
doença alérgica é complexa e multifatorial e envolve uma interação entre múltiplos fatores genéticos e ambientais. ${ }^{1-4}$ Sabe-se que o aleitamento materno exclusivo, durante os primeiros seis meses de vida, é um fator protetor para o desenvolvimento destas doenças. ${ }^{4-5}$

A prevalência de doença alérgica na população pediátrica é elevada ${ }^{6-7}$ e apresenta a seguinte distribuição: 7-8\% alergias do tipo alimentar, $15-20 \%$ atopia/eczema e $31-34 \%$ asma/sibilância recorrente. ${ }^{7}$ Representa um

1 - Médica Assistente de Medicina Geral e Familiar. Centro de Saúde do Monte,ACeS Região Autónoma da Madeira

2 - Médica Interna de Medicina Geral e Familiar. Centro de Saúde do Caniço, ACeS Região Autónoma da Madeira importante problema de saúde pública pelo impacto na vida dos indivíduos afetados, sendo uma causa frequente de absentismo escolar e laboral. ${ }^{4,7}$

Vários estudos sugerem que o uso de fórmulas hidrolisadas (constituídas por péptidos derivados de proteínas do leite de vaca caracteristicamente menos imunogénicas) ${ }^{2,8-9} \mathrm{em}$ lactentes cuja alimentação não é realizada exclusivamente com leite materno pode reduzir o desenvolvimento de doença alérgica. ${ }^{6-7}$ Contudo, o uso destas fórmulas não é consensual na comunidade científica.

Este trabalho tem como objetivo rever a evidência existente acerca da eficácia da suplementação com fórmulas hidrolisadas na prevenção de doença alérgica em crianças de termo. 


\section{MÉTODOS}

Pesquisa bibliográfica sistemática, realizada em março de 2019, de normas de orientação clínica, meta-análises, revisões sistemáticas e ensaios clínicos aleatorizados e controlados, limitados a estudos em humanos. Foram pesquisados artigos publicados entre janeiro de 2009 e janeiro de 2019, em inglês, nas bases de dados The Cochrane Database, MEDLINE/PubMed, National Guideline Clearinghouse, Guideline Finder e Canadian Medical Association.

O query de pesquisa incluiu os ter-

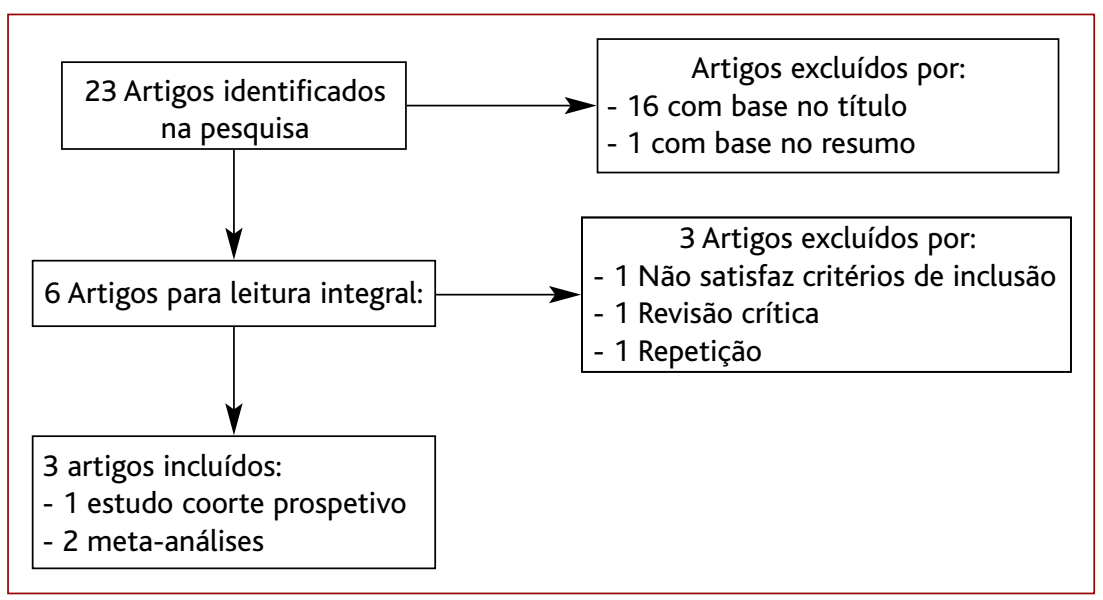

Figura 1. Organigrama de seleção dos artigos. mos MeSH: Protein hydrolysates; Hypersensitivity; Allergy and immunology; Rhinitis; Allergic, Seasonal; Asthma.

Os critérios de inclusão foram: lactentes de termo (população), utilização de leite hidrolisado (intervenção), fórmula convencional de leite de vaca/leite materno (comparação), redução da doença alérgica (outcome). Os critérios de exclusão foram: lactentes pré-termo e doença alérgica documentada antes do estudo. Para a atribuição dos níveis de evidência e forças de recomendação utilizou-se a Strenght of Recomendation Taxonomy, da American Academy of Family Physicians (SORT).

\section{RESULTADOS}

Foram obtidos 23 artigos, dos quais três cumpriram os critérios de inclusão: duas meta-análises e um estudo de coorte. O organigrama de seleção dos artigos está representado na Figura 1 e os resultados estão descritos nas Tabelas 1 e 2 .

Em 2010, Berg e colaboradores² realizaram um estudo coorte prospetivo duplamente cego, com o objetivo de avaliar o impacto da alimentação no desenvolvimento de eczema atópico. A amostra incluiu 5.991 crianças nascidas em duas regiões da Alemanha entre setembro de 1995 e junho de 1998, com e sem predisposição familiar para alergia. As crianças com predisposição familiar para doença alérgica, cujos pais aceitaram participar no estudo, constituíram o grupo submetido a intervenção e foi-lhes aleatoriamente atribuído, após o nascimento, um dos seguintes tipos de

fórmula: leite de vaca $v s$ leite parcialmente hidrolisado $v s$ leite extensamente hidrolisado $(n=2.252)$. As restantes 3.739 crianças, com e sem predisposição familiar para doença alérgica, representaram o grupo não submetido a intervenção alimentar. Verificou-se que as crianças com predisposição familiar para doença alérgica, que não receberam intervenção nutricional com fórmula parcialmente hidrolisada ou extensamente hidrolisada, apresentaram um risco 2,1 vezes superior de desenvolver eczema do que as crianças sem história familiar de alergia e que o risco de eczema foi menor no grupo com intervenção alimentar. Apesar dos resultados positivos do estudo foi-lhe atribuído um nível de evidência 2 , uma vez que ao fim de seis anos menos de $80 \%$ das crianças mantinham seguimento, não se podendo obter resultados estatisticamente significativos.

Vandenplas e colaboradores ${ }^{10}$ realizaram, em 2014, uma revisão sistemática que incluiu três estudos (revisões sistemáticas), com um total de aproximadamente 11.964 participantes, todos crianças com elevado ou sem risco de doença alérgica.

- Um dos estudos avaliou o efeito da utilização de fórmula hidrolisada $v s$ leite materno $v s$ fórmula convencional de leite de vaca durante um curto período e demonstrou que nas crianças de baixo risco não existe diferença estatisticamente significativa no desenvolvimento de doença alérgica no primeiro ano de vida. Porém, no mesmo estudo, a utilização prolongada (4-6 meses) de fórmula convencional de leite de vaca $v s$ fórmula parcialmente hidrolisada em crianças com elevado risco de doença alérgica 


\begin{tabular}{|c|c|c|c|c|c|c|}
\hline Referência & $\begin{array}{l}\text { Tipo de } \\
\text { estudo }\end{array}$ & População & $n$ & Intervenção & Resultados & NE \\
\hline $\begin{array}{l}\text { Berg et al. } \\
(2010)^{2}\end{array}$ & $\begin{array}{l}\text { Estudo } \\
\text { coorte } \\
\text { prospetivo }\end{array}$ & $\begin{array}{l}\text { Crianças nascidas } \\
\text { entre 09/95 e } \\
\text { 06/98 em duas } \\
\text { regiões da } \\
\text { Alemanha }\end{array}$ & $\begin{array}{l}\text { Sem intervenção } \\
(n=3.739) ; \\
\text { Com intervenção e } \\
\text { história familiar } \\
\text { positiva para } \\
\text { doença alérgica } \\
(n=2.252) ; \\
n=5.991 \text { (total) }\end{array}$ & $\begin{array}{l}\text { Ao nascer foi } \\
\text { atribuída uma } \\
\text { fórmula infantil: } \\
\text { FCLV vs FPH vs } \\
\text { FEH }\end{array}$ & $\begin{array}{l}\text { Crianças com predisposição } \\
\text { familiar para doença alérgica, sem } \\
\text { intervenção nutricional, tiveram } \\
\text { um risco } 2,1 \text { superior de } \\
\text { desenvolver eczema do que } \\
\text { crianças sem história familiar. O } \\
\text { risco foi menor quando houve } \\
\text { intervenção nutricional. }\end{array}$ & 2 \\
\hline
\end{tabular}

Legenda: $\mathrm{ECA}$ = Estudo controlado e aleatorizado; FCLV = Fórmula convencional de leite de vaca; $\mathrm{FEH}=$ Fórmula extensamente hidrolisada; FPH = Fórmula parcialmente hidrolisada; NE = Nível de evidência.

\begin{tabular}{|c|c|c|c|c|}
\hline Referência & Estudo & Intervenção & Resultados & NE \\
\hline $\begin{array}{l}\text { Osborn et al. } \\
(2018)^{7}\end{array}$ & $\begin{array}{l}\text { MT } \\
16 \text { estudos } \\
\text { (11 ECA e } \\
5 \mathrm{EQE})\end{array}$ & $\begin{array}{l}n=9.563 \text { (total) lactentes de termo } \\
\text { Suplementação com FEH vs leite materno; } \\
\text { Suplementação com FEH vs FCLV; } \\
\text { Alimentação prolongada com FH vs FCLV. }\end{array}$ & $\begin{array}{l}\text { Sem evidência que apoie a utilização de FEH } \\
\text { vs leite materno e FEH vs FCLV na prevenção } \\
\text { de doença alérgica. Informação limitada, } \\
\text { sugere que em lactentes alimentados com } \\
\text { FCLV a utilização de FEH pode reduzir a } \\
\text { doença alérgica infantil. }\end{array}$ & 2 \\
\hline $\begin{array}{l}\text { Vandenplas } \\
\text { et al. } \\
(2014)^{10}\end{array}$ & $8 \mathrm{RS}$ & $\begin{array}{l}\mathrm{n}=11.964 \text { (total) crianças com e sem risco } \\
\text { de doença alérgica } \\
\mathrm{FCLV} \text { vs FH }\end{array}$ & $\begin{array}{l}\text { Determinadas fórmulas de caseína } \\
\text { extensamente hidrolisada e parcialmente } \\
\text { hidrolisadas Whey podem reduzir o risco de } \\
\text { doença alérgica em crianças de alto risco. O } \\
\text { mesmo não se aplica a crianças de baixo } \\
\text { risco de doença alérgica, por falta de estudos } \\
\text { neste grupo. }\end{array}$ & 2 \\
\hline
\end{tabular}

Legenda: $\mathrm{ECA}=$ Estudo controlado e aleatorizado; $\mathrm{EQE}=$ Estudo quase-experimental; $\mathrm{FCLV}$ = Fórmula convencional de leite de vaca; $\mathrm{FEH}=$ Fórmula extensamente hidrolisada; FH = Fórmula hidrolisada; MT = Meta-análise; RS = Revisão sistemática.

demonstrou que havia redução estatisticamente significativa da doença alérgica até ao primeiro ano de vida (RR=0,79; IC95\%, 0,66-0,94).

- Uma revisão sistemática que foi incluída, com 12 populações independentes em estudo, analisou a associação de dermatite atópica e a utilização de fórmula parcialmente hidrolisada Wheye verificou que havia redução estatisticamente significativa da doença alérgica [11 estudos (RR=0,56; IC95\%, 0,4-0,77) e quatro estudos (RR=0,45; IC95\%, 0,30-0,70)].
- Outro dos estudos comparou o efeito das fórmulas parcialmente hidrolisadas Whey vs fórmula convencional e revelou uma redução estatisticamente significativa de doença alérgica em diferentes grupos etários: 3-6 meses (cinco ECA; RR=0,48; IC95\%, 0,23-1,00); 12 meses (quatro ECA; RR=0,62; IC95\%, 0,45$-0,85$ ) e 30-36 meses (um ECA; RR $=0,42$; IC95\%, 0,19$-0,90)$.

Foi atribuído um nível de evidência 2 a esta revisão sistemática pelo facto de conter estudos de baixa 
qualidade, com amostras de pequenas dimensões e ter aspetos pouco claros na metodologia.

Uma meta-análise da Cochrane, realizada por Osborn e colaboradores, ${ }^{7}$ em 2018, incluiu um total de dezasseis estudos. Onze destes foram estudos controlados aleatorizados e cinco estudos quase-experimentais, tendo envolvido um total de 9.563 lactentes. O objetivo desta meta-análise era comparar os efeitos na doença alérgica em crianças alimentadas com fórmulas hidrolisadas $v s$ fórmula convencional de leite de vaca ou leite materno.

Como resultados obteve-se o seguinte:

- Dois estudos avaliaram o efeito da suplementação com fórmula infantil extensamente hidrolisada $v s$ leite materno durante três a quatro dias após o nascimento, concluindo que não houve diferença estatisticamente significativa no desenvolvimento de doença alérgica (RR=1,43; IC95\%, 0,38-5,37). Quando comparado o efeito da suplementação com fórmula infantil extensamente hidrolisada $v s$ fórmula convencional de leite de vaca concluíram que também não havia diferenças estatisticamente significativas no desenvolvimento de doença alérgica $(\mathrm{RR}=1,37$; IC95\%, 0,33-5,71). No entanto, os autores consideram que estas conclusões são de baixa qualidade, uma vez que consideram existir potenciais vieses e imprecisões nos estudos utilizados.

- Os restantes estudos avaliaram o efeito da alimentação prolongada com fórmula infantil hidrolisada $v s$ fórmula convencional de leite de vaca, mas também não revelaram diferenças estatisticamente significativas no desenvolvimento de doença alérgica em lactentes $(\mathrm{RR}=0,88 ; \mathrm{IC} 95 \%, 0,76-1,01)$ e crianças (RR=0,85; IC95\%, 0,69-1,05). A análise de subgrupos encontrou algumas evidências do benefício da alimentação prolongada e exclusiva com fórmula hidrolisada comparativamente à fórmula com proteínas do leite de vaca, associada a uma redução de alergia alimentar (mas não do eczema, asma ou rinite); contudo, existem poucos ensaios clínicos que avaliem o efeito da alimentação exclusiva com fórmula hidrolisada, de modo que a evidência é insuficiente para uma análise adequada. Novamente houve potenciais vieses e imprecisões nos estudos selecionados; por isso, a qualidade da evidência também foi considerada fraca.
As autoras atribuíram um nível de evidência 2 à meta-análise, uma vez que a qualidade da evidência dos estudos utilizados foi considerada de baixa qualidade pelos próprios autores por potenciais vieses e imprecisões nos estudos utilizados. Outro dos problemas está relacionado com a dimensão das amostras utilizadas nos estudos selecionados, sendo por vezes demasiado pequenas.

\section{CONCLUSÕES}

Alguns estudos sugerem que a suplementação com leite hidrolisado poderá reduzir o risco de doença alérgica; contudo, após a análise dos mesmos não foi estabelecida uma relação causal, em grande parte devido ao tipo, desenho e validade dos estudos.

Atualmente não existe evidência científica que apoie a utilização de suplementação com leite hidrolisado na prevenção de doença alérgica. Esta afirmação tem força de recomendação B, pois a evidência disponível sobre esta temática carece de estudos metodologicamente adequados, robustos e de alta qualidade que validem a evidência encontrada.

\section{REFERÊNCIAS BIBLIOGRÁFICAS}

1. von Berg A. Modified proteins in allergy prevention. In: Brandtzaeg P, Isolauri E, Prescott SL, editors. Microbial host-interaction: tolerance versus allergy (64th Nestlé Nutrition Institution Workshop, Pediatric Program, Sydney, November 2008). Basel: Karger; 2009. p. 239-50.

2. Berg A, Krämer U, Link E, Bollrath C, Heinrich J, Brockow I, et al. Impact of early feeding on childhood eczema: development after nutritional intervention compared with the natural course - the GINIplus study up to the age of 6 years. Clin Exp Allergy. 2010;40(4):627-36.

3. Becker A, Watson W, Ferguson A, Dimich-Ward H, Chan-Yeung M. The Canadian asthma primary prevention study: outcomes at 2 years of age. J Allergy Clin Immunol. 2004;113(4):650-6.

4. Halken S. Prevention of allergic disease in childhood: clinical and epidemiological aspects of primary and secondary allergy prevention. Pediatr Allergy Immunol. 2004;15 Suppl 16:4-5, 9-32.

5. Muraro A, Agache I, Clark A, Sheikh A, Roberts G, Akdis C, et al. EAACl food allergy and anaphylaxis guidelines: managing patients with food allergy in the community. Allergy. 2014;69(8):1046-57.

6. Prescott SL, Tang ML. The Australasian Society of Clinical Immunology and Allergy position statement: summary of allergy prevention in children. Med J Aust. 2005;182(9):464-7.

7. Osborn DA, Sinn JK, Jones LJ. Infant formulas containing hydrolysed protein for prevention of allergic disease and food allergy. Cochrane Database Syst Rev. 2018;(10):CD003664.

8. Lowe AJ, Hosking CS, Bennett CM, Allen KJ, Axelrad C, Carlin JB, et al. Effect of a partially hydrolyzed whey infant formula at weaning on risk of allergic disease in high-risk children: a randomized controlled trial. J 
Allergy Clin Immunol. 2011;128(2):360-5.e4.

9. Boyle RJ, Tang ML, Chiang WC, Chua MC, Ismail I, Nauta A, et al. Prebiotic supplemented partially hydrolysed cow's milk formula for the prevention of eczema in high risk infants: a randomized controlled trial. Allergy. 2016;71(5):701-10.

10. Vandenplas Y, Bhatia J, Shamir R, Agostoni C, Turck D, Staiano A, et al. Hydrolyzed formulas for allergy prevention. J Pediatr Gastroenterol Nutr. 2014;58(5):549-52.

\section{CONFLITO DE INTERESSES}

Os autores declaram não ter quaisquer conflitos de interesses.

\section{FINANCIAMENTO}

O trabalho relatado neste manuscrito não foi objeto de qualquer tipo de financiamento externo (incluindo bolsas e investigação).

\section{ENDEREÇO PARA CORRESPONDÊNCIA}

Luciana Ornelas

E-mail: luciana.jvornelas@gmail.com

https://orcid.org/0000-0001-5876-495X

Recebido em 02-05-2019

Aceite para publicação em 05-08-2020

\section{ABSTRACT}

\section{THE HYDROLYZED FORMULA FOR THE PREVENTION OF ALLERGIC DISEASE IN PEDIATRIC AGE: AN EVIDENCE-BASED REVIEW}

Objective: Review the existing evidence on the efficacy of supplementation with hydrolyzed formulas in the prevention of allergic disease in non-premature children.

Data sources: The Cochrane Database, MEDLINE/PubMed, National Guideline Clearinghouse, Guideline Finder, and the Canadian Medical Association.

Methods: A search for randomized controlled trials, meta-analyses, systematic reviews, and clinical guidelines, published between January 2009 and January 2019 in English and limited to human studies. We used the search query with the MeSH terms: Protein Hydrolysates; Hypersensitivity; Allergy and Immunology; Rhinitis; Allergic, Seasonal; Asthma. The Strength of Recommendation Taxonomy (SORT) of the American Family Physician was used to evaluate the quality and the strength of the recommendation of the studies.

Results: Of 23 articles found, three met the inclusion criteria: two meta-analyses and a cohort study. Only one of the included studies presented statistically significant results in the reduction of allergic disease. The remaining studies have not shown evidence in reducing allergic disease.

Conclusions: After analyzing the articles, it was concluded that there is no scientific evidence on the use of hydrolyzed milk supplementation for the prevention of allergic disease (recommendation force B). It is considered that more studies in this area, with better quality, are necessary to validate the evidence found and help to formulate other hypotheses.

Keywords: Hydrolyzed formula; Allergic disease. 